\title{
Discussion on the Practical Teaching Reform on the Art Design Course of "Materials and Technologies" in Colleges and Universities
}

\author{
Xue Gao \\ School of Art Design \\ Sias International College \\ Zhengzhou University \\ Xinzheng, China 451150
}

\begin{abstract}
Materials and Technologies" is an important professional compulsory course in the product design specialty in colleges and universities. The purpose of this course is to make students know and understand the product materials and master some basic forming and processing technologies. Although all universities have opened the course, but most of the product design graduates do not understand materials and technologies well. When they join in work, their designs are too rigid in real projects. Employers are not willing to accept fresh graduates, so that a lot of fresh graduates are difficult to find a job. Aiming at this problem, the paper has given some suggestions. Our colleges and universities can adopt the enterprise-school cooperation mode and make full use of the enterprises as practice base and other practice teaching resources to help students understand the importance of materials and technologies in depth from this course and really grasp the knowledge of materials, to improve their practical ability and thus lay a solid foundation for employment.
\end{abstract}

Keywords-school-enterprise cooperation; materials and technologies; practical teaching

\section{INTRODUCTION}

"Materials and Technologies" is a practical course, which is a course for all students of art design in colleges and universities. It is especially important for students of product design. The course is generally set in linking stage between the professional basic courses and the specialized core courses, which mainly aims at making students understand the knowledge of product materials and technologies and apply the materials with different characteristics in design. It is a conversion process from design plan to material expression. The significance of opening this course is undoubtedly, but most of product design graduates do not understand materials and technologies well. When they join in work, their designs are too rigid in real projects. Graduates can not quickly locate the relationship of product materials, business production and market, so employers have to retrain them. Thus, a lot of fresh graduates are difficult to find a job. If students can master the actual design and making process and are sensitive to real materials and technologies in school, it will be helpful for them in work. It is a thing worth our educators' profound thinking.

\section{PRoblems IN THE COURSE OF "MATERIALS AND TECHNOLOGIES"}

\section{A. The Unreality of the Simulation Projects}

The design projects that most students access and teachers arrange are generally assumed "real projects". Students do not contact with enterprises and markets. Even though they can make beautiful and vivid design sketch and lifelike models, they hardly pass the cost accounting of enterprises and the feasibility analysis of materials and technologies. Their works can only be used to participate in design contest and to gain an honor, but can not put into practical production. Students are difficult to know the relationship of designers, enterprises and markets.

\section{B. The Difference of Materials \& Technologies and Model Making Concept}

Many colleges and universities open the course of "Materials and Technologies" in product design. Carefully seen their teaching outline and teaching plan, we will find their focus falls in model making. At the same time, students may find some cheep materials to cope with the projects to save money. After the finish of course, they have threedimensional models but with crude processing. Even they know nothing about their original design, product material and technologies, let alone put their design works into production. In concept, "model production" should be part of the "materials and technologies". In the course of "materials and technologies", teachers should first guide students to understand the diversity of product materials. Material categories are not just limited to sludge, ABS and other common model materials. With the rapid development of modern industry, the types of materials become more and more abundant, and the methods of modeling and processing technologies are also changing with each passing day. 


\section{The Short Period of Course Time, Insufficient Practice Equipment And Lack of Subsequent Training}

Generally there are a period of $4 \sim 6$ weeks for "materials and technologies". As a large class of materials course, only class explanation and simple model making can not solve the problem. If we want to carry out practice on all kinds of materials and technologies, the existing teaching resources can hardly meet the conditions. Each material needs a production system in the production of products. In general, the equipment is expensive and large in size. And the replacement of the equipment is fast, so it is not real for teaching supporting laboratory to keep the synchronization with the social production. In this course, it is very necessary to open students view in a period, and then list and sort different varieties and technologies, and help students master the methods. After the finish of course, it is necessary to give students subsequent professional projects to continue their learning on materials and technologies.

\section{The Poor Hands-On Ability}

It has been a major problem for students. Many students focus on the creation of concept contests. It is understandable for students to improve professional design level actively. Most students can draw pictures and make computer drawing, but once they deal with real materials, they will be afraid. Even it is difficult for them to control some simple model, let alone to master some special materials. The laboratories in colleges and universities are generally equipped with some basic material processors and tools. And most often colleges and universities will take security of students and cost into consideration. Many of the existing tools and materials can not be arbitrarily used. As a result, students do not attach importance to model and even fear to make model. Because most models students have made can not reach to their assumed effect. When they join work, they may often suffer setbacks. The reason mainly lies on their poor understanding of actual production.

\section{The Course GoAl OF "MATERIALS AND}

\section{TECHNOLOGIES" IN THE SCHOOL-ENTERPRISE COOPERATION} MODE

It is an effective solution to existing problems in course of "materials and technologies" to implement the schoolenterprise cooperation mode in education, for it can make full use of practical teaching resources, such as practice base, and improve students practical experience. The cooperation between schools and enterprises is getting closer and closer in recent years. In particular, some managers of enterprises believe the school's fresh power can bring some innovative points to enterprises. On the one hand, it can realize resource complementary and then achieve the technological innovation. On the other hand, it can bring different results to both sides in the research. A lot of enterprises apply for cooperation with colleges and universities and establish practice base. There are a lot of practice bases for students of product design in colleges and universities, such as design companies, furniture factories, toy companies, and ceramic enterprises. To a large extent, these companies need creative plans to continuously update their products and thus obtain the advantages in the market. However, from the current level of cooperation, it is still difficult to achieve the desired effect. Because the current curriculum setting of colleges and universities is still subject to the constraints of classroom discipline and school attendance system. It is difficult to combine classroom practice and practice base. This makes the practice base nominal, and there are only a few opportunities for cooperation. It needs some practical courses to play the function of "school-enterprise cooperation".

\section{THE IMPLEMENTATION METHODS OF "MATERIALS AND TECHNOLOGIES" IN THE SCHOOL-ENTERPRISE COOPERATION MODE}

\section{A. The Investigation Stage}

In the primary stage of the course, teachers certainly need to explain a lot about product materials and various processing techniques. But they are all art students who attend university by participating in art examinations, so they are accustomed to use their sense thinking, and are not interested in logic and mathematical theory knowledge, even hard to deal with them. At this time, if we can transfer knowledge into real material investigation through practice base, it will inevitably stimulate students' interest. Students can understand the materials in textbooks or finished product markets from materials selection of production source, stepby-step processing, and finally processing into a finish product. We can invite different materials manufacturers or technical personnel of enterprises to teach our students. The technical personnel in first line of production can attract students' interest in learning.

\section{B. The Planning and Drafting Stage}

Through visit, students have a direct experience on some materials and technologies. At this time, colleges and universities can cooperate with design companies, thus provide platform for students to participate in practice. We can divide students into several groups and give them real tasks. We can assess students with enterprises' attendance system, rewards and punishment measures. This real enterprise atmosphere can help students adapt to the workplace atmosphere as soon as possible. Due to the reality of projects, students shall take a certain responsibility, which can enhance the students' sense of responsibility. The students can use the learned product design methods to start task analysis and market survey, and make draft according to results. In the primary, students take materials and technologies into consideration. The projects have real limitations because of real demand of enterprises, so students need to take practical function of materials and cost of processing into consideration. Students need to communicate with enterprises or clients directly to understand situations, so that make optimal design program.

\section{The Effect Picture Stage}

After the plan is determined, students should make the rendering effect more close to the effect of real object in making three-dimensional model effect picture with computer software. At this stage, the responsible person of 
enterprise or clients can clearly see the design effect and put forward the relevant amendments. In the stage of making 3D model effect, we can train students conversion ability from two dimensional sketch, effect picture to real threedimensional model, and help students lay a good foundation in real object production by use the draft mode made by raw materials.

\section{The Object Production Stage}

Take ceramic technology as example. Students can play clay with their hands in factory, and it helps them understand the difference of hand kneading technology, casting technology and molding technology. Many modeling means can be selected according to the plan. In the firing process, different firing temperatures can create different glaze effects. In this process, there may be some defects and problems with different processing methods. But these are valuable lessons that can be learned only in real production. For another example, some furniture manufacturers use different processing methods to process different materials, including wood, fiber, plastic and etc. In the plan, students shall consider texture, hardness, ductility and other characteristics of materials in function design. Whether the technology can meet the design expectations needs to be verified in the production process. Each step involves the quality of the finished product and cost control. Students can learn a lot of knowledge and memorize it profoundly. The learning effect is far more vivid than that of textbooks. The entire production process can also fully reflect the outstanding resources provided by the enterprise. Relatively, it needs a lot of money for school to buy equipment and tools, cover wear of tools and post maintenance, and they are direct factors affecting the production effect. However, practice bases can provide all-round conditions, so that students needn't worry about the limitations on equipment and tools. What's more, teachers and the technical works in first line can give guidance to students, which give guarantee to the implementation of students' design plan.

\section{E. The Summary Stage}

At the end of this course, students should first master diversity of materials and different technologies. Then through researching one specific material, students can experience relevant models and methods and understand the processing technology. As a conclusion, every material has its unique characteristics, and students need to speed a lot of time to study, so that they can flexibly select materials and apply into technologies according to the demand of the plan. They may meet a lot of difficulties in the making process, but they are good opportunity for them to learn the relationship of materials and technologies. There are some features in course score setting. The score can be divided into several parts. On the one hand, teachers can assess students through program plan and report to know their levels on materials and technologies. On the other hand, enterprises can assess students according their staff standards, and by checking whether students' investigation report and program process is concern about the production process and market analysis, as well as by daily attendance scores. So, scores can reflect students' achievement in a comprehensive manner. In the cooperation, enterprises may gain new products. Some designs can be put into market after they are improved and promoted, and gain economic benefits.

\section{THE COURSE SignifiCANCE OF MATERIALS AND TECHNOLOGIES IN THE SCHOOL-ENTERPRISE COOPERATION MODE}

After the production of the product object, all design reports can be demonstrated directly. Enterprise's cost accounting and client's evaluation after use can bring very significant effect to the course of "materials and technologies", and it is very helpful for the systematic training of entire design curriculum. For enterprises, the cooperation with school can first promote the cognition for enterprises and expand the influence of enterprises. At the same time, students' innovative programs may produce new direction of production, which has a good effect on the benefit of enterprises. For schools, they can save a lot of money on equipment for laboratory, and give strong support for training students roundly. The school-enterprise cooperation teaching can help enterprise find talents. After class or in holiday, they can select some excellent students for paid practice. Students can communicate with interested enterprises and adapt to occupational environment as soon as possible, and find their employment target. This schoolenterprise cooperation mode can make full use of effective resources of schools and enterprises, and school and enterprises can achieve win-win results.

Any product design can not be carried out without material. The learning of materials and technologies can expand the design direction of designers and enhance their confidence. Products need to restore the beauty of the material and let users appreciate the functionality of material. Good product design can combine material characteristics and functions perfectly. The end of the course does not mean the end of course teaching. There are wide categories of modern product materials. The teaching of "materials and technologies" should be concluded in every professional course. The school-enterprise mode should also be used in every design course, so that students can know different materials and technologies through design programs. Students can not only observe and know materials and technologies, but also participate into design and production with enterprises' real project, teachers' guidance and technical support of factories, and thus accumulate knowledge of materials and technologies. When they graduate, students can become an all-round applied designer who can directly participate in production and know production technologies, rather than a graphic designer.

\section{REFERENCES}

[1] Zhang Jun. Research on the Teaching Reform of "Materials and Technologies" in New Catalogue of Product Design. Journal of Lanzhou Institute of Education, 2014 (4).

[2] Ai Qing. Thinking of the Teaching Methods of Art Materials and Technologies. Science and Education: Mid-month Journal, 2012 (5). 